\title{
Differentiation of species of the family Acetobacteraceae by AFLP DNA fingerprinting: Gluconacetobacter kombuchae is a later heterotypic synonym of Gluconacetobacter hansenii
}

\author{
Ilse Cleenwerck, ${ }^{1}$ Marjan De Wachter, ${ }^{1}$ Ángel González, ${ }^{2}$ Luc De Vuyst ${ }^{2}$ \\ and Paul De Vos ${ }^{1,3}$ \\ ${ }^{1}$ BCCM/LMG Bacteria Collection, Faculty of Sciences, Ghent University, K. L. Ledeganckstraat 35, \\ B-9000 Ghent, Belgium \\ ${ }^{2}$ Research Group of Industrial Microbiology and Food Biotechnology, Department of Applied \\ Biological Sciences and Engineering, Vrije Universiteit Brussel, Pleinlaan 2, B-1050 Brussels, \\ Belgium \\ ${ }^{3}$ Laboratory of Microbiology, Faculty of Sciences, Ghent University, K. L. Ledeganckstraat 35, \\ B-9000 Ghent, Belgium
}

Correspondence

Ilse Cleenwerck

ilse.cleenwerck@ugent.be

\begin{abstract}
Amplified fragment length polymorphism (AFLP) DNA fingerprinting was investigated as a tool for fast and accurate identification of acetic acid bacteria $(A A B)$ to the species level. One hundred and thirty five reference strains and 15 additional strains, representing 50 recognized species of the family Acetobacteraceae, were subjected to AFLP analysis using the restriction enzyme combination Apal/ Taql and the primer combination A03/T03. The reference strains had been previously subjected to either DNA-DNA hybridization or 16S-23S rRNA spacer region gene sequence analysis and were regarded as being accurately classified at the species level. The present study revealed that six of these strains should be reclassified, namely Gluconacetobacter europaeus LMG 1518 and Gluconacetobacter xylinus LMG 1510 as Gluconacetobacter xylinus and Gluconacetobacter europaeus, respectively; Gluconacetobacter kombuchae LMG $23726^{\top}$ as Gluconacetobacter hansenii; and Acetobacter orleanensis strains LMG 1545, LMG 1592 and LMG 1608 as Acetobacter cerevisiae. Cluster analysis of the AFLP DNA fingerprints of the reference strains revealed one cluster for each species, showing a linkage level below $50 \%$ with other clusters, except for Acetobacter pasteurianus, Acetobacter indonesiensis and Acetobacter cerevisiae. These three species were separated into two, two, and three clusters, respectively. At present, confusion exists regarding the taxonomic status of Gluconacetobacter oboediens and Gluconacetobacter intermedius; the AFLP data from this study supported their classification as separate taxa. The 15 additional strains could all be identified at the species level. AFLP analysis further revealed that some species harboured genetically diverse strains, whereas other species consisted of strains showing similar banding patterns, indicating a more limited genetic diversity. It can be concluded that AFLP DNA fingerprinting is suitable for accurate identification and classification of a broad range of AAB, as well as for the determination of intraspecific genetic diversity.
\end{abstract}

\footnotetext{
Abbreviations: $A A B$, acetic acid bacteria; AFLP, amplified fragment length polymorphism; ERIC enterobacterial repetitive intergenic consensus sequences; FAFLP, fluorescent amplified fragment length polymorphism; RAPD, randomly amplified polymorphic DNA; REP, Repetitive extragenic palindromic sequences.

The GenBank/EMBL/DDBJ accession number for the 16S rRNA gene sequence of LMG $23726^{\top}$ is AM999342.

A supplementary figure showing the (GTG) $)_{5}-\mathrm{PCR}$ fingerprints of strains belonging to the species of the Gluconacetobacter xylinus branch and supplementary tables detailing the DNA-DNA relatedness of the strains of the genera Acetobacter and Gluconacetobacter as determined in this and previous studies are available with the online version of this paper.
}

Acetic acid bacteria (AAB) are Gram-negative, coccoid or rod-shaped, obligate aerobic bacteria that have the ability to incompletely oxidize a wide range of carbohydrates, alcohols and sugar alcohols. They are involved in the production of several fermented foods and beverages, either in a beneficial (vinegars, cocoa-based products, Kombucha and nata de coco) or detrimental (spoilage of beer, wine and cider) manner and are also used in the production of commercially important fine chemicals and bacterial cellulose. Recently, some AAB have been 
described as human pathogens (Greenberg et al., 2006; Kersters et al., 2006; Tuuminen et al., 2007).

At the time of writing, $\mathrm{AAB}$ are classified into ten genera comprising 52 recognized species in the family Acetobacteraceae of the class Alphaproteobacteria, i.e. the genera Acetobacter (19 species), Acidomonas (1 species), Asaia (4 species), Gluconacetobacter (16 species), Gluconobacter (7 species), Granulibacter (1 species), Kozakia (1 species), Neoasaia (1 species), Saccharibacter (1 species) and Swaminathania (1 species) (Cleenwerck et al., 2007, 2008; Dutta \& Gachhui, 2007; Ndoye et al., 2007; Malimas et al., 2007, 2008a, b; Cleenwerck \& De Vos, 2008; Yamada \& Yukphan, 2008).

Multiple studies have shown that accurate identification of $\mathrm{AAB}$ isolates is difficult (Moore et al., 2002; Greenberg et al., 2006; Kersters et al., 2006; Tuuminen et al., 2006; Cleenwerck \& De Vos, 2008). While identification to the genus level can generally be achieved by $16 \mathrm{~S}$ rRNA gene sequence analysis and/or some phenotypic tests (Kersters et al., 2006; Cleenwerck \& De Vos, 2008; Yamada \& Yukphan, 2008), identification to the species level can be problematic (Kersters et al., 2006; Cleenwerck \& De Vos, 2008). Species identifications based solely on phenotypic data are not recommended and, for this reason, several authors have advised the use of genotypic data as the basis for species identification of $\mathrm{AAB}$ (Cleenwerck \& De Vos, 2008).

In the last decade, researchers have therefore increasingly abandoned phenotypic tests or have complemented them by the use of molecular DNA-based methods. DNA-DNA hybridizations and sequence analysis of $16 \mathrm{~S}$ rRNA genes, 16S-23S rRNA gene spacer regions and genes such as adh $A$ [encoding subunit I of pyrroloquinoline quinone (PQQ)dependent alcohol dehydrogenase] and $r e c A$ (encoding the DNA repair protein RecA) have been applied, as well as DNA fingerprinting techniques such as RFLP analysis of PCR-amplified rRNA (mainly 16S rRNA genes and 16S23S rRNA gene spacer regions), randomly amplified polymorphic DNA (RAPD) fingerprinting, rep-PCR using the $(\mathrm{GTG})_{5}$, REP (repetitive extragenic palindromic sequences) and ERIC (enterobacterial repetitive intergenic consensus sequences) primers, PFGE and plasmid profiling (reviewed by Cleenwerck \& De Vos, 2008). However, for many methods, the taxonomic resolution is not completely clear, because its evaluation has often been based on a set of strains with insufficient representatives per taxon and lacking phylogenetic relatives. Nevertheless, it is likely that the resolution power of techniques based on 16S rRNA genes will not reach the species level, especially since high $16 \mathrm{~S}$ rRNA gene sequence similarities have been found between several species of the family (Cleenwerck \& De Vos, 2008). For rapid identification and classification of a broad range of $A A B$, the most appropriate technique at present appears to be rep-PCR using the $(\mathrm{GTG})_{5}$ primer (De Vuyst et al., 2008).

Amplified fragment length polymorphism (AFLP) DNA fingerprinting, a universally applicable technique with a high discriminatory power and good reproducibility (Janssen et al., 1996; Savelkoul et al., 1999), has proved to be useful for discrimination at the species level and below in various taxa such as the genera Aeromonas, Acinetobacter, Campylobacter, Xanthomonas (Savelkoul et al., 1999), Vibrionaceae (Thompson et al., 2001), Bradyrhizobium (Willems et al., 2001), Arcobacter (On et al., 2003) and Pantoea (Brady et al., 2007).

In the present study, $150 \mathrm{AAB}$ (Table 1), representing 50 recognized species of the family Acetobacteraceae, were analysed by AFLP DNA fingerprinting, with the aim of investigating whether this technique could deliver fast and accurate identification and classification of $\mathrm{AAB}$ to the species level. For 135 of these strains, DNA-DNA hybridization data or 16S-23S rRNA gene spacer region sequence analysis data have been reported previously (Urakami et al., 1989; Sievers et al., 1992; Boesch et al., 1998; Sokollek et al., 1998; Franke et al., 1999; Navarro et al., 1999; Lisdiyanti et al., 2000, 2001, 2002, 2006; Schüller et al., 2000; Yamada et al., 2000; Fuentes-Ramírez et al., 2001; Katsura et al., 2001; Cleenwerck et al., 2002, 2007, 2008; Trček \& Teuber, 2002; Loganathan \& Nair, 2004; Jojima et al., 2004; Yukphan et al., 2004, 2005; Dellaglio et al., 2005; Muthukumarasamy et al., 2005; Sievers \& Swings, 2005; Dutta \& Gachhui, 2006, 2007; Greenberg et al., 2006; Silva et al., 2006; Takahashi et al., 2006; Camu et al., 2007; Malimas et al., 2007; Ndoye et al., 2007; De Vuyst et al., 2008). Therefore, these strains were assumed to be accurately classified at the species level and were regarded as reference strains for the purpose of this study. The 150 strains used in this study were obtained from the BCCM/LMG Bacteria Collection and the Research Collection of the Laboratory of Microbiology (LM-UGent) or were kindly provided by the German Collection of Microorganisms and Cell Cultures (DSMZ). They were cultivated on GY ( $5 \%$ glucose, $1 \%$ yeast extract, $1.5 \%$ agar; w/v) or GYAE (5\% glucose, $1 \%$ yeast extract, $1.5 \%$ agar; w/v; $2 \%$ ethanol, $1 \%$ acetic acid; v/v; the latter two components were sterilized separately by filtration and added aseptically to the autoclaved medium) and in some cases on the medium suggested by the provider, by incubation at $28{ }^{\circ} \mathrm{C}$ under aerobic conditions.

Fluorescent amplified fragment length polymorphism (FAFLP) DNA fingerprinting of whole genomes was performed on genomic DNA extracted following the method of Wilson (1987) with minor modifications. Briefly, a loopful of cells was washed with RS buffer (0.15 M NaCl, 10 mM EDTA, pH 8.0) and then suspended in a $360 \mu \mathrm{l}$ mix containing $340 \mu \mathrm{l} 10 \mathrm{mM}$ Tris/HCl, $25 \mathrm{mM}$ EDTA, pH 8.0, $16 \mu \mathrm{l}$ RNaseA solution $\left(10 \mathrm{mg} \mathrm{ml}^{-1}\right.$; Sigma) and $4.0 \mu \mathrm{l}$ proteinase $\mathrm{K}$ solution (Merck). A $40 \mu \mathrm{l}$ aliquot of preheated $\left(37^{\circ} \mathrm{C}\right) \mathrm{SDS} / \mathrm{TE}$ solution $(20 \%$ SDS in $10 \mathrm{mM}$ Tris/ $\mathrm{HCl}, 1 \mathrm{mM}$ EDTA, $\mathrm{pH} 8.0 ; \mathrm{w} / \mathrm{v})$ was added to the mixture and the whole sample was incubated at $37^{\circ} \mathrm{C}$ for $60 \mathrm{~min}$. After visual verification of cell lysis, $120 \mu \mathrm{l} 5 \mathrm{M} \mathrm{NaCl}$ was added and mixed by inversion, before the addition of $80 \mu \mathrm{l}$ CTAB/ 
Fig. 1. AFLP DNA fingerprints of strains representing 50 recognized species of the family Acetobacteraceae (figure has been split over two pages). The dendrogram was constructed with the UPGMA method after calculation of the band pattern similarity (\%) using the DICE coefficient. *, strain for which no DNA-DNA hybridization data or 16S-23S rRNA gene spacer region sequence analysis data have (previously) been reported; $\dagger$, strain reclassified on the basis of data presented in this study; $¥$, strain identified on the basis of AFLP DNA fingerprint data obtained in this study.

$\mathrm{NaCl}$ solution (10\% hexadecyltrimethylammonium bromide in $0.7 \mathrm{M} \mathrm{NaCl}$; w/v). After $20 \mathrm{~min}$ incubation at $65{ }^{\circ} \mathrm{C}$, the lysate was subjected to a phenol/chloroform/isoamylalcohol $(49: 49: 1)$ extraction using Phase Lock Gel tubes (Eppendorf). A $10 \mu \mathrm{l}$ aliquot of RNase A solution (10 $\mathrm{mg} \mathrm{ml}^{-1}$; Sigma) was added to the carefully transferred aqueous phase and after 15-30 min incubation at $37{ }^{\circ} \mathrm{C}$, the solution was again subjected to a phenol/ chloroform/isoamylalcohol $(49: 49: 1)$ extraction using Phase Lock Gel tubes. The aqueous phase was carefully transferred and mixed with $500 \mu \mathrm{l}$ ice-cold $100 \%$ 2propanol and kept on ice for $15 \mathrm{~min}$. Pellets were collected by centrifugation, washed in ice-cold $70 \%$ ethanol, dried and resuspended in 50-200 $\mu \mathrm{l} 0.1 \times \mathrm{TE}$ solution, depending on the size of the pellet. DNA concentration and purity were estimated by measuring the absorptions at $260 \mathrm{~nm}$, $280 \mathrm{~nm}$ and $234 \mathrm{~nm}$. DNA concentration and size were additionally verified by agarose gel electrophoresis using a $1 \%(\mathrm{w} / \mathrm{v})$ agarose gel. For Gluconacetobacter entanii LTH $4560^{\mathrm{T}}$, DNA according to the descriptions of Gluconacetobacter swingsii and Gluconacetobacter rhaeticus (Dellaglio et al., 2005) was used. Template DNA was prepared using the restriction enzyme combination ApaI/ TaqI essentially as described previously (Janssen et al., 1996). Briefly, $1 \mu \mathrm{g}$ high-molecular-mass DNA was digested with TaqI/ApaI, followed by ligation of the corresponding double-stranded restriction half-site adaptors (Janssen et al., 1996) using T4 ligase (Amersham Pharmacia Biotech). Template DNA was precipitated in a solution containing $100 \mu \mathrm{l}$ T0.1E $\quad(10 \mathrm{mM}$ Tris/HCl, $0.1 \mathrm{mM}$ EDTA, $\mathrm{pH} \mathrm{8.0)}$ and used for selective PCR amplification with the primer combination A03/T03. Both these primers consist of a core region (A-, T-primer core sequences, see Janssen et al., 1996) and a guanine extension at the $3^{\prime}$-end. The A03 primer was labelled with the fluorescent label 6-FAM at the $5^{\prime}$-end. The amplification mixture contained $1.5 \mu \mathrm{l}$ template DNA, $0.5 \mu \mathrm{l} 4 \mu \mathrm{M}$ hexaprimer, $0.5 \mu \mathrm{l} 1 \mu \mathrm{M}$ tetraprimer and $7.5 \mu \mathrm{l}$ Amplification Core Mix (Applied Biosystems). The amplification reactions were performed in a GeneAmp PCR system 9700 thermocycler using the 9600 mode (Applied Biosystems) and the temperature program described previously (Thompson et al., 2001). Selective PCR products were separated using PAGE as described previously (Thompson et al., 2001). Using GENESCAN 3.1 software (Applied Biosystems), the resulting AFLP DNA fingerprints were tracked and normalized, and bands were assigned and sized. Tables with information on the fragments of $50-536 \mathrm{bp}$ were transferred into the
BioNumerics 4.61 software (Applied Maths) for numerical analysis. Fingerprint similarity values were calculated using the DICE coefficient with a position tolerance of $0.2 \%$ to compensate for technical imperfections (optimization tolerance: $0 \%$ ), and a dendrogram was constructed using the unweighted pair group method using arithmetic means (UPGMA). The zone between 60 and $500 \mathrm{bp}$ was used for comparison.

AFLP DNA fingerprinting has previously been reported to be a highly reproducible technique, making it very suitable for the generation of databases for identification purposes (Janssen et al., 1996; Savelkoul et al., 1999). In this study, the AFLP DNA fingerprints of 35 strains were generated twice, starting from a new DNA isolation, and genomic DNA of Gluconacetobacter azotocaptans LMG $21311^{\mathrm{T}}$ was included in each set of DNA that was subjected to AFLP analyses. The similarity between fingerprints obtained for the same strain, after assignment of bands, ranged between 80 and $95 \%$, except for strains producing a lot of cellulose, such as Gluconacetobacter swingsii LMG $22125^{\mathrm{T}}$ and Gluconacetobacter intermedius LMG $18909^{\mathrm{T}} \quad$ (=DSM $\left.11804^{\mathrm{T}}\right)$. In these cases, the similarity value was sometimes lower $(70 \%)$. Nevertheless, AFLP profiles of the same strain still clustered together when all of the AFLP DNA fingerprints generated were considered, except if other strains generated very similar profiles (with band pattern similarity above the reproducibility level), suggesting that the strains could be clonally related.

The AFLP DNA fingerprints of the 150 strains, as well as an UPGMA dendrogram obtained after cluster analysis of these patterns, are shown in Fig. 1. Most strains (>80\%) generated patterns containing between 40 and 100 bands, evenly distributed in the range of 50-536 bp. Strains generating fewer bands generally belong to the genus Acetobacter. For Acetobacter pasteurianus, the current restriction enzyme combination and primer combination appeared not to be very suitable, as several strains generated profiles containing mainly larger bands (>200 bp; e.g. A13), while others generated less than 15 bands (e.g. A33).

Nevertheless, the reference strains of a particular species generated profiles that grouped in clusters according to their respective taxonomic designations, with only a few exceptions. Firstly, the species Acetobacter pasteurianus and Acetobacter indonesiensis were each divided over two AFLP groups (Table 1). Both species have been previously shown to contain genetically diverse strains (Trček \& Teuber, 2002; De Vuyst et al., 2008). For Acetobacter pasteurianus, 


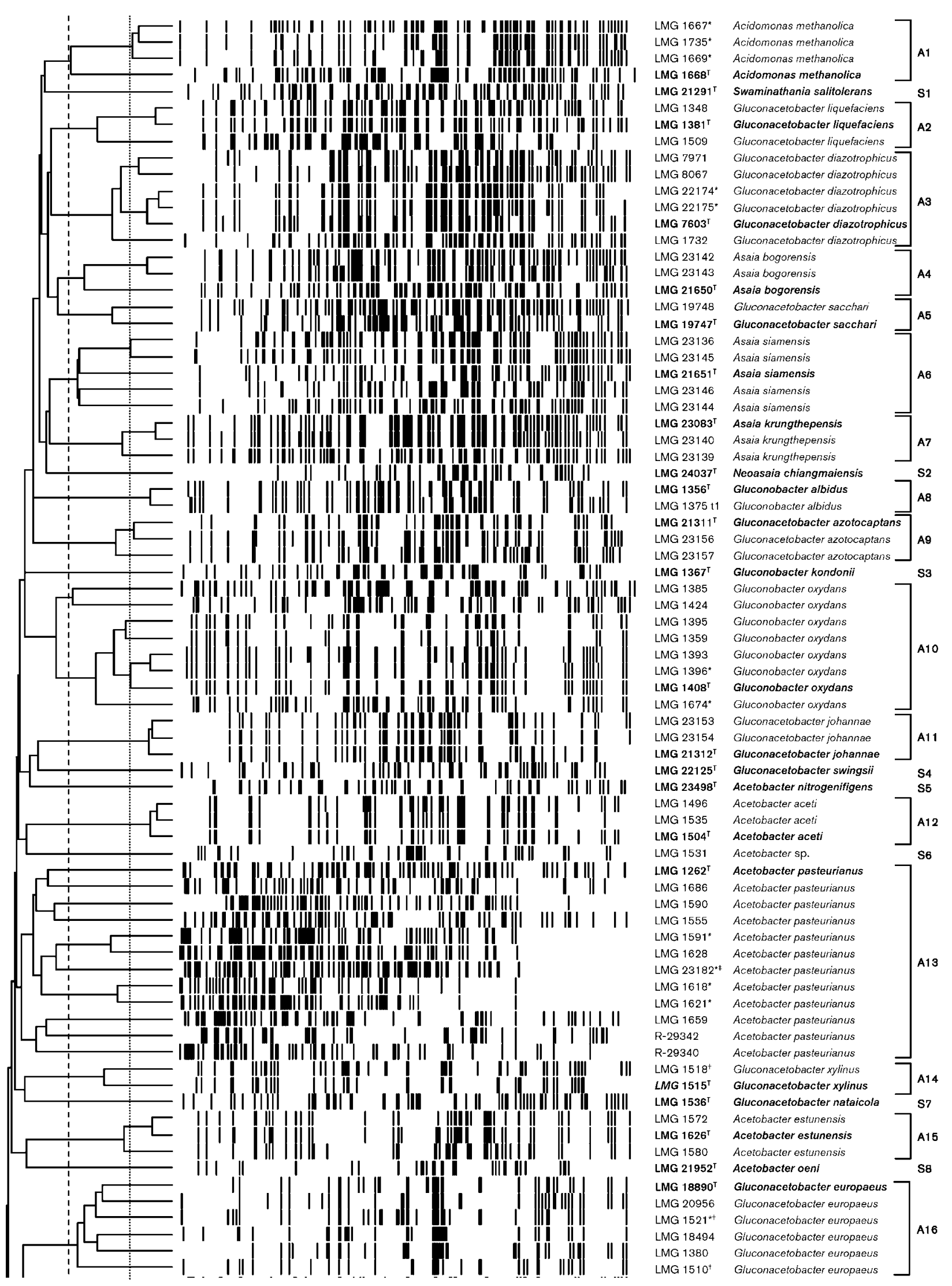




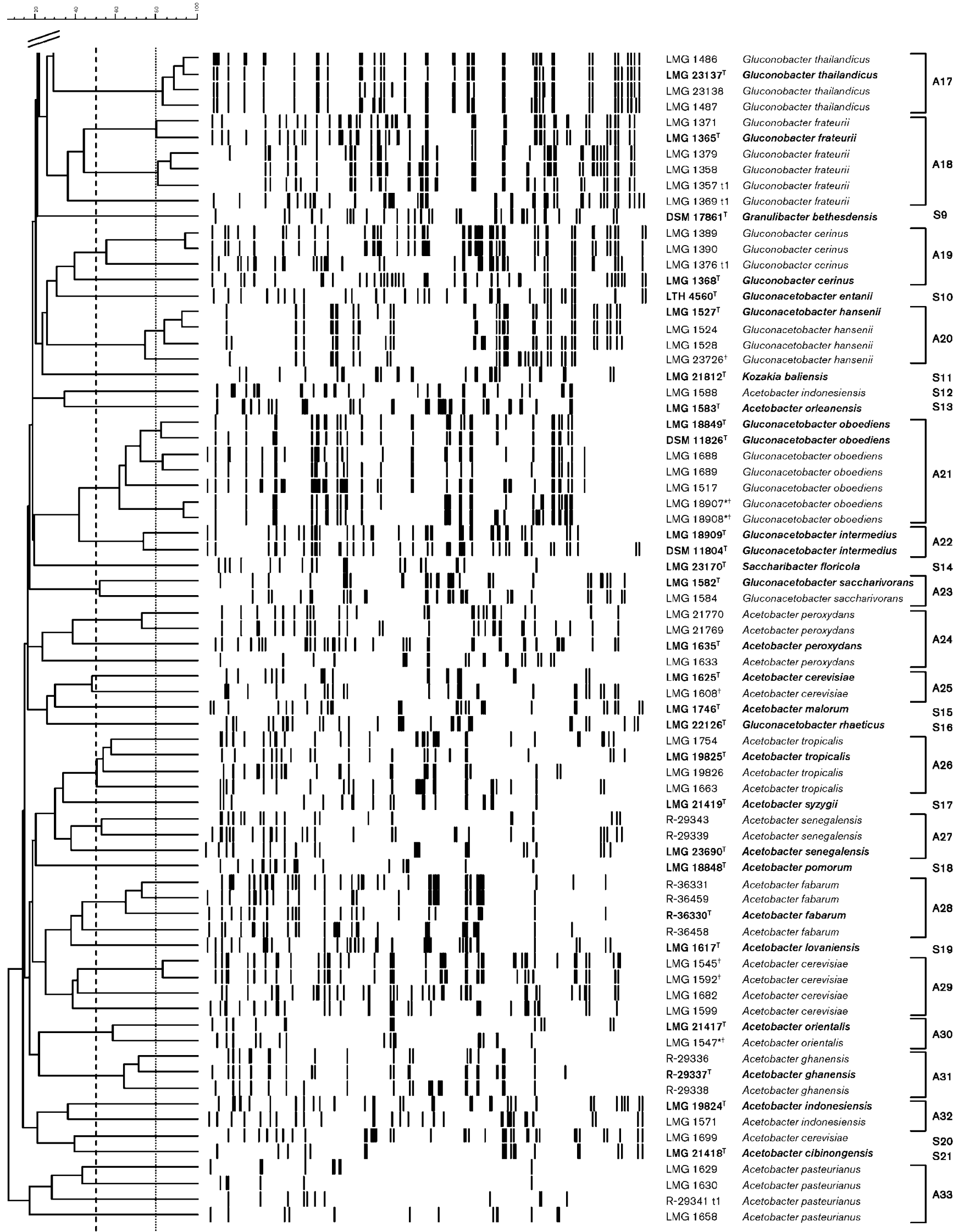


this has also been found to be reflected in the DNA relatedness values which range from 62-90\% (Cleenwerck et al., 2002). Secondly, strains of the species Acetobacter cerevisiae (LMG 1599, LMG $1625^{\mathrm{T}}$, LMG 1682, LMG 1699) and Acetobacter orleanensis (LMG 1545, LMG $1583^{\mathrm{T}}$, LMG 1592, LMG 1608), two phenotypically similar and phylogenetically closely related species, as well as Gluconacetobacter europaeus LMG 1518, Gluconacetobacter xylinus LMG 1510 and Gluconacetobacter kombuchae LMG $23726^{\mathrm{T}}$ (Table 1), did not cluster as expected from their species designation and were, therefore, investigated in more detail (see below). It appeared that six of these strains should be reclassified, namely strains LMG 1545, LMG 1592 and LMG 1608 as Acetobacter cerevisiae; LMG 1518 and LMG 1510 as Gluconacetobacter xylinus and Gluconacetobacter europaeus, respectively; and LMG $23726^{\mathrm{T}}$ as Gluconacetobacter hansenii. After reassignment of these reference strains, the species Acetobacter cerevisiae splits up over three AFLP groups (Table 1). Previous studies have suggested that species can be divided over different AFLP clusters (Thompson et al., 2001; Willems et al., 2001).

In total, 54 AFLP groups (A1 to A33, containing more than one strain; S1 to S21, each containing one strain) were delineated; each containing strains of the same species and showing a linkage level below $50 \%$ with other groups. Each species was represented by one AFLP group (except for Acetobacter pasteurianus, Acetobacter indonesienis and Acetobacter cerevisiae; see above). Strain LMG 1531 (S6), previously assigned to Acetobacter aceti but removed from this species based on $(\mathrm{GTG})_{5}$-PCR fingerprint data and its low DNA-DNA relatedness $(<60 \%)$ with true Acetobacter aceti strains (De Vuyst et al., 2008), showed a separate position, hereby confirming its status as a novel genospecies of Acetobacter (Wayne et al., 1987; Stackebrandt et al., 2002). Overall, the results with the reference strains revealed the potential of AFLP for the identification and classification of $\mathrm{AAB}$ at the species level.

Analysis of the AFLP data of the 15 additional strains proved the taxonomic value of this AFLP approach, as all 15 strains could be identified at the species level. Ten strains clustered according to their original taxonomic assignment; while four strains (Acetobacter pasteurianus LMG 1547, Gluconacetobacter intermedius LMG 18907 and LMG 18908, and Gluconacetobacter xylinus LMG 1521) did not (Table 1); these appeared all to be misclassified (see below). Finally, LMG 23182, deposited in the BCCM/LMG Bacteria Collection as Acetobacter sp. (Table 1), could be identified as Acetobacter pasteurianus, a result that was expected from other research (E. J. Bartowsky, personal communication).

The AFLP data revealed, as mentioned above, several strains that did not cluster as expected from their species designation. These strains were subjected to additional tests including DNA-DNA hybridizations if appropriate (see Supplementary Tables S1 and S2 in IJSEM Online). DNADNA hybridizations were performed following a modi- fication (Goris et al., 1998; Cleenwerck et al., 2002) of the microplate method described by Ezaki et al. (1989) with high-molecular-mass genomic DNA, with $A_{260} / A_{280}$ and $A_{234} / A_{260}$ absorption ratios of $1.8-2.0$ and $0.40-0.60$ DNA, prepared according to the method of Wilson (1987) with minor modifications (Cleenwerck et al., 2002). The hybridization temperature was $48{ }^{\circ} \mathrm{C}$ and hybridizations were performed in the presence of $50 \%$ formamide. Reciprocal reactions (e.g. $\mathrm{A} \times \mathrm{B}$ and $\mathrm{B} \times \mathrm{A}$ ) were performed for every pair of DNA samples and their variation was found to be within the limits of this method (Goris et al., 1998). The additional tests revealed ten strains that have to be reclassified (see below).

Strains LMG 1545 (A29), LMG 1592 (A29) and LMG 1608 (A25) were classified as Acetobacter orleanensis, mainly on the basis of DNA-DNA hybridization data (Lisdiyanti et al., 2000), however their AFLP DNA fingerprints clustered with those of Acetobacter cerevisiae strains, instead of with that of Acetobacter orleanensis LMG $1583^{\mathrm{T}}$ (Fig. 1). DNADNA hybridizations performed in this study with strains LMG $1625^{\mathrm{T}}$, LMG $1583^{\mathrm{T}}$, LMG 1682, LMG 1545 and LMG 1608 confirmed the classification of strain LMG 1682 as Acetobacter cerevisiae (DNA relatedness of $88 \%$ with Acetobacter cerevisiae LMG $1625^{\mathrm{T}}$ versus $34 \%$ with Acetobacter orleanensis LMG $1583^{\mathrm{T}}$ ), and revealed that strains LMG 1545 and LMG 1608 should be reclassified in Acetobacter cerevisiae (see Supplementary Table S1). Strain LMG 1592 should also be reclassified as Acetobacter cerevisiae as its AFLP DNA fingerprint showed $>80 \%$ band pattern similarity with that of LMG 1545 .

Strains LMG 1518 (A14) and LMG 1510 (A16) were classified as Gluconacetobacter europaeus and Gluconacetobacter xylinus, respectively, on the basis of DNA-DNA hybridization data and (GTG) $)_{5}$ PCR DNA fingerprint data (De Vuyst et al., 2008). In the present study, AFLP analyses were performed for both strains starting from two newly opened LMG ampoules and on the DNA samples used in the study of De Vuyst et al. (2008). The DNA fingerprint data revealed that strains LMG 1518 and LMG 1510 should be reassigned to Gluconacetobacter xylinus and Gluconacetobacter europaeus, respectively. The previous taxonomic conclusions appear to have been based on erroneous results (suggesting a switch during DNA isolation or strain cultivation).

Strain LMG $23726^{\mathrm{T}}$ (A20) is the type strain and only strain of Gluconacetobacter kombuchae (Dutta \& Gachhui, 2007). Its AFLP DNA fingerprint clustered with the AFLP patterns of strains belonging to Gluconacetobacter hansenii, its phylogenetically nearest neighbour $(99.4 \% 16 \mathrm{~S}$ rRNA gene sequence similarity), indicating that these strains could actually represent the same species and that the names are synonymous. Additional tests confirmed this synonymy. First, a nearly complete $16 \mathrm{~S}$ rRNA gene sequence of Gluconacetobacter kombuchae LMG $23726^{\mathrm{T}}$ was determined (1441 nucleotides, GenBank accession no. AM999342) following the protocol described by Franz et al. (2006) 
Table 1. List of $A A B$ used in this study

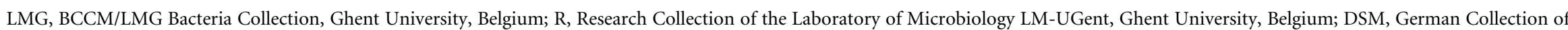

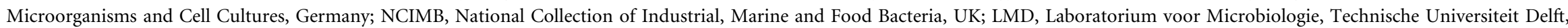

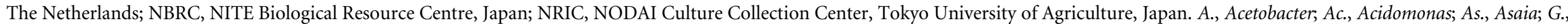
Gluconacetobacter; Gl., Gluconobacter; Gr., Granulibacter; K., Kozakia; N., Neoasaia; S., Saccharibacter; Sw., Swaminathania.

\begin{tabular}{|c|c|c|c|c|c|}
\hline Strain numbers & $\begin{array}{l}\text { Species designation at the } \\
\text { time of selection }\end{array}$ & Year, place and source of isolation & $\begin{array}{l}\text { Hybridization } \\
\text { group }\end{array}$ & AFLP group & $\begin{array}{c}\text { Proposed species } \\
\text { designation }\end{array}$ \\
\hline LMG 1496 (=LMG 24WR) & A. aceti & & A. aceti & A12 & A. aceti \\
\hline LMG $1504^{\mathrm{T}}\left(=\right.$ NCIMB $8621^{\mathrm{T}}=$ NBRC $\left.14818^{\mathrm{T}}\right)$ & A. aceti & 1923; beech-wood shavings of vinegar plant & A. aceti & $\mathrm{A} 12$ & A. aceti \\
\hline LMG 1535 (=LMG Ch31) & A. aceti & Belgium; vinegar plant & A. aceti & $\mathrm{A} 12$ & A. aceti \\
\hline LMG 1531 (=NCIMB 8941) & Acetobacter sp. & Cider & Related to A. aceti & S6 & Acetobacter sp. \\
\hline LMG 1545 (=NBRC 3296=NBRC 3296) & A. orleanensis & 1941; Aichi, Japan; film in fermenter of rice vinegar & A. cerevisiae & A29 & A. cerevisiae \\
\hline LMG 1592 (=NCIMB 2224=NBRC 3170) & A. orleanensis & Manufacture of vinegar & & A29 & A. cerevisiae \\
\hline LMG 1599 (=NCIMB 6425) & A. cerevisiae & UK; brewers' yeast and beer & A. cerevisiae & A29 & A. cerevisiae \\
\hline LMG $1608(=$ NCIMB $8088=$ NBRC 3223$)$ & A. orleanensis & 1932; Netherlands; beer & A. cerevisiae & A25 & A. cerevisiae \\
\hline LMG $1625^{\mathrm{T}}\left(=\mathrm{NCIMB} 8894^{\mathrm{T}}\right)$ & A. cerevisiae & Toronto, Canada; beer (ale) in storage & A. cerevisiae & A 25 & A. cerevisiae \\
\hline LMG $1682(=\mathrm{C} 101)$ & A. cerevisiae & Ireland; beer & A. cerevisiae & A29 & A. cerevisiae \\
\hline LMG 1699 (=MARTIN 2) & A. cerevisiae & 1977; UK; brewery & A. cerevisiae & S20 & A. cerevisiae \\
\hline LMG $21418^{\mathrm{T}}\left(=4 \mathrm{H}-1^{\mathrm{T}}\right)$ & A. cibinongensis & Indonesia; mountain soursop (Annona montanae) & A. cibinongensis & S21 & A. cibinongensis \\
\hline LMG 1572 (=LMG E) & A. estunensis & Bristol, UK; cider & A. estunensis & A15 & A. estunensis \\
\hline LMG 1580 (=LMD 50.6) & A. estunensis & 1950; Leiden, Netherlands; beer & A. estunensis & A15 & A. estunensis \\
\hline LMG $1626^{\mathrm{T}}\left(=\mathrm{NCIMB} 8935^{\mathrm{T}}=\operatorname{NBRC} 13751^{\mathrm{T}}\right)$ & A. estunensis & Bristol, UK; cider & A. estunensis & A15 & A. estunensis \\
\hline $\mathrm{R}-36330^{\mathrm{T}}\left(=\mathrm{LMG} 24244^{\mathrm{T}}=985^{\mathrm{T}}\right)$ & A. fabarum & 2006; Ghana; fermented cocoa beans & A. fabarum & $\mathrm{A} 28$ & A. fabarum \\
\hline R-36331 (=1145) & A. fabarum & 2006; Ghana; fermented cocoa beans & A. fabarum & A28 & A. fabarum \\
\hline R-36458 (=950) & A. fabarum & 2006; Ghana; fermented cocoa beans & A. fabarum & A28 & A. fabarum \\
\hline R-36459 (=1039) & A. fabarum & 2006; Ghana; fermented cocoa beans & A. fabarum & $\mathrm{A} 28$ & A. fabarum \\
\hline $\mathrm{R}-29336(=444 \mathrm{~B})$ & A. ghanensis & 2004; Ghana; fermented cocoa beans & A. ghanensis & A31 & A. ghanensis \\
\hline $\mathrm{R}-29337^{\mathrm{T}}\left(=\mathrm{LMG} 23848^{\mathrm{T}}=430 \mathrm{~A}^{\mathrm{T}}\right)$ & A. ghanensis & 2004; Ghana; fermented cocoa beans & A. ghanensis & A31 & A. ghanensis \\
\hline R-29338 (=415) & A. ghanensis & 2004; Ghana; fermented cocoa beans & A. ghanensis & A31 & A. ghanensis \\
\hline LMG 1571 (=LMD 39.2) & A. indonesiensis & & A. indonesiensis & A32 & A. indonesiensis \\
\hline LMG 1588 (=LMD 39.6) & A. indonesiensis & & A. indonesiensis & S12 & A. indonesiensis \\
\hline LMG $19824^{\mathrm{T}}\left(=\right.$ NRIC $\left.0313^{\mathrm{T}}=5 \mathrm{H}-1^{\mathrm{T}}\right)$ & A. indonesiensis & Indonesia; fruit of zirzak (Annona muricata) & A. indonesiensis & $\mathrm{A} 32$ & A. indonesiensis \\
\hline LMG $1617^{\mathrm{T}}\left(=\operatorname{NCIMB} 8620^{\mathrm{T}}=\operatorname{NBRC} 13753^{\mathrm{T}}\right)$ & A. lovaniensis & 1929; Becquevoort, Belgium; sewage on soil & A. lovaniensis & S19 & A. lovaniensis \\
\hline LMG $1746^{\mathrm{T}}\left(=\right.$ LMG $\left.76.10^{\mathrm{T}}\right)$ & A. malorum & 1976; Ghent, Belgium; rotting apple & A. malorum & S15 & A. malorum \\
\hline LMG $23498^{\mathrm{T}}\left(=\mathrm{RG}^{\mathrm{T}}\right)$ & A. nitrogenifigens & 2004; India; Kombucha tea & A. nitrogenifigens & S5 & A. nitrogenifigens \\
\hline LMG $21952^{\mathrm{T}}\left(=\mathrm{B} 13^{\mathrm{T}}\right)$ & A. oeni & 2002; Viseu Dão region, Portugal; spoiled red wine & A. oeni & S8 & A. oeni \\
\hline LMG $21417^{\mathrm{T}}\left(=21 \mathrm{~F}-2^{\mathrm{T}}\right)$ & A. orientalis & Indonesia; canna flower (Canna hybrida) & A. orientalis & $\mathrm{A} 30$ & A. orientalis \\
\hline LMG $1547^{\star}(=$ LMD 39.1) & A. pasteurianus & & A. orientalis & $\mathrm{A} 30$ & A. orientalis \\
\hline LMG $1583^{\mathrm{T}}\left(=\right.$ NCIMB $8622^{\mathrm{T}}=$ NBRC $\left.13752^{\mathrm{T}}\right)$ & A. orleanensis & 1927; Belgium; beer & A. orleanensis & S13 & A. orleanensis \\
\hline LMG $1262^{\mathrm{T}}\left(=\mathrm{LMD} 22.1 \mathrm{t1}^{\mathrm{T}}\right)$ & A. pasteurianus & Netherlands; beer & A. pasteurianus & $\mathrm{A} 13$ & A. pasteurianus \\
\hline LMG 1555 (=NCIMB 8163) & A. pasteurianus & & A. pasteurianus & A13 & A. pasteurianus \\
\hline LMG 1590 (=LMD 51.1) & A. pasteurianus & Type strain of A. pasteurianus subsp. ascendens & & A13 & A. pasteurianus \\
\hline
\end{tabular}


Table 1. cont.

LMG $1591^{\star}(=$ LMD 53.6)

LMG $1618^{\star}(=$ NCIMB 8757$)$

A. pasteurianus

Quick vinegar; type strain of $A$. pasteurianus subsp.

paradoxus

LMG $1621^{*}$ (=NCIMB 8760)
LMG 1628 (=NCIMB 9015)

A. pasteurianus

A. pasteurianus

A. pasteurianus

LMG $1629(=\mathrm{A})$

LMG 1630 (=EQ)

LMG 1658 (=MM 80)

LMG 1659 (=MM 73)

A. pasteurianus

A. pasteurianus

A. pasteurianus

A. pasteurianus

A. pasteurianus Acetobacter sp.

A. pasteurianus

A. pasteurianu

A. pasteurianu

A. peroxydans

$\mathrm{R}-29342(=406)$

LMG 1633

$\begin{array}{ll}\text { LMG } 1635^{\mathrm{T}}\left(=\mathrm{NCIMB} 8618^{\mathrm{T}}=\mathrm{NBRC} 13755^{\mathrm{T}}\right) & \text { A. peroxydans } \\ \text { LMG } 21769(=\mathrm{TNCSF} 36) & \text { A. peroxydans }\end{array}$

LMG 21770 (=TNCSF 49)

A. peroxydans

A. pomorum

A. senegalensis

LMG $23690^{\mathrm{T}}\left(=\mathrm{CWBI}-\mathrm{B} 418^{\mathrm{T}}\right)$

A. senegalensis

A. senegalensis

A. syzygii

$\mathrm{R}-29343(=420 \mathrm{~A})$

LMG $21419^{\mathrm{T}}\left(=9 \mathrm{H}-2^{\mathrm{T}}\right)$

LMG $1663(=592)$

A. tropicalis

A. tropicalis

A. tropicalis

A. tropicalis

LMG $19825^{\mathrm{T}}\left(=\right.$ NRIC $\left.0312^{\mathrm{T}}=\mathrm{Ni}-6 \mathrm{~b}^{\mathrm{T}}\right)$

LMG 19826 (=NRIC 0321)

Ac. methanolica

Ac. methanolica

LMG $1668^{\mathrm{T}}\left(=\right.$ MB $58^{\mathrm{T}}=$ IMET $\left.10945^{\mathrm{T}}\right)$

Ac. methanolica

Ac. methanolica

As. bogorensis

UK; malt vinegar acetifier

UK; malt vinegar acetifier

Recife, Brazil; fermented Agave sisalina juice

Recife, Brazil; sugar cane bagasse

Myanmar; toddy palm

Myanmar; toddy palm

1928; Netherlands; vinegar from dry raisins

1997; Australia; oxidized Shiraz wine showing spoilage

2004; Ghana; fermented cocoa beans

2004; Ghana; fermented cocoa beans

2004; Ghana; fermented cocoa beans

1950; Netherlands; ditch water

Delft, Netherlands; ditch water

1999-2000; Thirumangalam Madurai,Tamilnadu,

India; Oryza sativa, root tissue

1999-2000; Villupuram Villupuram, Tamilnadu,

India; Oryza sativa, root tissue

Esslingen, Germany; submerged cider vinegar

fermentation

1995; Casamance, Senegal; mango fruit (Mangifera indica)

2004; Ghana; fermented cocoa beans

2004; Ghana; fermented cocoa beans

Indonesia; fruit of Malay rose apple (Syzygium

malaccense)

UK; fermenting putrefied meat

1979; Ivory Coast; fruit of Ficus capensis

Indonesia; coconut juice

Indonesia; lime

Sludge

Leipzig, Germany; fermentation of methanol with

Candida sp. (not sterile)

LMG $1669^{*}(=$ MB 60)

LMG $1735^{\star}(=$ SRI 1214$)$

LMG $21650^{\mathrm{T}}\left(=71^{\mathrm{T}}\right)$
Sludge

Australia; Saccharum officinarum, surface microflora

Bogor, Indonesia; flower of the orchid tree (Bauhinia purpurea)
A. pasteurianus

A. pasteurianus

A. pasteurianus

A. pasteurianus

A. pasteurianus

A. pasteurianus

A. pasteurianus

Border of $A$.

pasteurianus

Border of $A$.

pasteurianus

A. pasteurianus

A. pasteurianus

A. pasteurianus

A. pasteurianus

Border of $A$.

peroxydans

A. peroxydans

A. peroxydans

A. peroxydans

A. pomorum

A. senegalensis

A. pasteurianus

A13

A. pasteurianus

A. pasteurianus

A. pasteurianus

A. pasteurianus

A. pasteurianus

A. peroxydans

A. peroxydans

A. peroxydans

A. peroxydans

A. pomorum

A. senegalensis

A. senegalensis

A. senegalensis

A. syzygii

A. senegalensis

A. senegalensis

A. syzygii

A. tropicalis

A. tropicalis

A. tropicalis

A. tropicalis

A. tropicalis

A. tropicalis

A. tropicalis

A. tropicalis

Ac. methanolica

Ac. methanolica

Ac. methanolica

Ac. methanolica

As. bogorensis 
Table 1. cont.

\begin{tabular}{|c|c|c|c|c|}
\hline Strain numbers & $\begin{array}{l}\text { Species designation at the } \\
\text { time of selection }\end{array}$ & Year, place and source of isolation & AFLP group & $\begin{array}{l}\text { Proposed species } \\
\text { designation }\end{array}$ \\
\hline LMG $23142(=87)$ & As. bogorensis & $\begin{array}{l}\text { Bogor, Indonesia; flower of plumbago (Plumbago } \\
\text { auriculata) }\end{array}$ & A4 & As. bogorensis \\
\hline LMG $23143(=168)$ & As. bogorensis & $\begin{array}{l}\text { Yogyakarta, Indonesia; tape ketan (fermented glutinous } \\
\text { rice) }\end{array}$ & A4 & As. bogorensis \\
\hline LMG $23083^{\mathrm{T}}\left(=\mathrm{AA} 08^{\mathrm{T}}\right)$ & As. krungthepensis & Bangkok, Thailand; Heliconia sp., flower & A7 & As. krungthepensis \\
\hline LMG 23139 (=AA06) & As. krungthepensis & Bangkok, Thailand; Heliconia sp., flower & A7 & As. krungthepensis \\
\hline LMG 23140 (=AA09) & As. krungthepensis & Bangkok, Thailand; Heliconia sp., flower & A7 & As. krungthepensis \\
\hline LMG $21651^{\mathrm{T}}\left(=\mathrm{S} 60-1^{\mathrm{T}}\right)$ & As. siamensis & Bangkok, Thailand; crown flower (Calotropis gigantea) & A6 & As. siamensis \\
\hline LMG $23136(=$ Y85) & As. siamensis & $\begin{array}{l}\text { Bogor, Indonesia; flower of spider lily (Crinum } \\
\text { asiaticum) }\end{array}$ & A6 & As. siamensis \\
\hline LMG $23144(=\mathrm{D} 4-1)$ & As. siamensis & $\begin{array}{l}\text { Bangkok, Thailand; flower of spider lily (Crinum } \\
\text { asiaticum) }\end{array}$ & A6 & As. siamensis \\
\hline LMG 23145 (=I36) & As. siamensis & $\begin{array}{l}\text { Bogor, Indonesia; flower of spider lily (Crinum } \\
\text { asiaticum) }\end{array}$ & A6 & As. siamensis \\
\hline LMG $23146(=$ B28S-3) & As. siamensis & Bogor, Indonesia; flower of ixora (Ixora chinensis) & A6 & As. siamensis \\
\hline LMG $21311^{\mathrm{T}}\left(=\mathrm{CFN}-\mathrm{Ca} 54^{\mathrm{T}}\right)$ & G. azotocaptans & $\begin{array}{l}\text { 1996; Tapachula Chiapas, Mexico; Coffea arabica L., } \\
\text { rhizosphere }\end{array}$ & A9 & G. azotocaptans \\
\hline LMG 23156 (=UAP-Ca97) & G. azotocaptans & $\begin{array}{l}\text { 1997; Motozintla Chiapas, Mexico; Coffea arabica L., } \\
\text { rhizosphere }\end{array}$ & A9 & G. azotocaptans \\
\hline LMG 23157 (=UAP-Ca99) & G. azotocaptans & $\begin{array}{l}\text { 1997; Motozintla Chiapas, Mexico; Coffea arabica L., } \\
\text { rhizosphere }\end{array}$ & A9 & G. azotocaptans \\
\hline LMG 1732 (=SRI 1205) & G. diazotrophicus & Australia, Saccharum officinarum, surface microflora & $\mathrm{A} 3$ & G. diazotrophicus \\
\hline LMG $7603^{\mathrm{T}}\left(=\right.$ Pal $\left.5^{\mathrm{T}}\right)$ & G. diazotrophicus & Alagoas, Brazil; Saccharum officinarum, root & A3 & G. diazotrophicus \\
\hline LMG 7971 (=PP 4) & G. diazotrophicus & Pernambuco, Brazil; Saccharum officinarum, stem & $\mathrm{A} 3$ & G. diazotrophicus \\
\hline LMG $8067(=$ PR 20) & G. diazotrophicus & Rio de Janeiro Brazil, Saccharum officinarum, root & $\mathrm{A} 3$ & G. diazotrophicus \\
\hline LMG $22174^{\star}(=$ TNCSF 42$)$ & G. diazotrophicus & $\begin{array}{l}\text { Thirumangalam Madurai,Tamilnadu, India; Oryza } \\
\text { sativa, root tissue }\end{array}$ & $\mathrm{A} 3$ & G. diazotrophicus \\
\hline LMG $22175^{\star}(=$ TNCSF 47$)$ & G. diazotrophicus & $\begin{array}{l}\text { Valajabad Kanchipuram,Tamilnadu, India, Oryza sativa, } \\
\text { stem tissue }\end{array}$ & $\mathrm{A} 3$ & G. diazotrophicus \\
\hline LTH $4560^{\mathrm{T}}$ & G. entanii & $\begin{array}{l}\text { Germany; submerged high-acid spirit vinegar } \\
\text { fermentation }\end{array}$ & S10 & G. entanii \\
\hline LMG 1380 (=NBRC 3261) & G. europaeus & 1941; Nishinomiya, Japan; Myrica rubra, fruit & A16 & G. europaeus \\
\hline LMG 1510 (=NCIMB 613) & G. xylinus & Copenhagen, Denmark; vinegar & A16 & G. europaeus \\
\hline LMG $1521^{*}(=$ NCIMB 7029) & G. xylinus & $\begin{array}{l}\text { Nairobi, Kenya; from mixed culture NCTC } 6716 \text { isolated } \\
\text { from vinegar brew }\end{array}$ & A16 & G. europaeus \\
\hline LMG 18494 (=Trcek V3) & G. europaeus & $\begin{array}{l}\text { 1995; Ljubljana, Slovenia; red wine vinegar produced in } \\
\text { submerged bioreactor }\end{array}$ & A16 & G. europaeus \\
\hline LMG $18890^{\mathrm{T}}\left(\right.$ DES $11^{\mathrm{T}}=$ DSM $\left.6160^{\mathrm{T}}\right)$ & G. europaeus & $\begin{array}{l}\text { Esslingen, Germany; submerged culture vinegar } \\
\text { generator }\end{array}$ & A16 & G. europaeus \\
\hline LMG 20956 (=JK2) & G. europaeus & $\begin{array}{l}\text { 1995; Ljubljana, Slovenia; cider vinegar produced in } \\
\text { industrial submerged bioreactor }\end{array}$ & A16 & G. europaeus \\
\hline
\end{tabular}




\begin{tabular}{|c|c|c|c|c|}
\hline Strain numbers & $\begin{array}{l}\text { pecies designation at the } \\
\text { time of selection }\end{array}$ & Year, place and source of isolation & AFLP group & $\begin{array}{c}\text { Proposed species } \\
\text { designation }\end{array}$ \\
\hline LMG 1524 (=NCIMB 8246=NBRC 14916) & G. hansenii & Jerusalem, Israel; vinegar & $\mathrm{A} 20$ & G. hansenii \\
\hline LMG $1527^{\mathrm{T}}\left(\right.$ NCIMB $8746^{\mathrm{T}}=$ NBRC $\left.14820^{\mathrm{T}}\right)$ & G. hansenii & $\begin{array}{l}\text { Cellulose-less mutant } 1 \text { derived from NCIB } 8745 \\
\text { isolated by M. Aschner, Jerusalem, vinegar }\end{array}$ & $\mathrm{A} 20$ & G. hansenii \\
\hline LMG $1528($ NCIMB 8747=NBRC 14817) & G. hansenii & $\begin{array}{l}\text { Cellulose-less mutant } 2 \text { derived from NCIB } 8745 \\
\text { isolated by M. Aschner, Jerusalem, vinegar }\end{array}$ & $\mathrm{A} 20$ & G. hansenii \\
\hline LMG 23726 (=RG3) & G. kombuchae & 2004; India; Kombucha tea fermentation & A20 & G. hansenii \\
\hline LMG $18909^{\mathrm{T}}\left(=\mathrm{TF}^{\mathrm{T}}\right)$ & G. intermedius $\dagger$ & $\begin{array}{l}\text { Switzerland; commercially available tea fungus beverage } \\
\text { (Kombucha) }\end{array}$ & $\mathrm{A} 22$ & G. intermedius \\
\hline $\operatorname{DSM} 11804^{\mathrm{T}}\left(=\mathrm{TF} 2^{\mathrm{T}}\right)$ & G. intermedius $\dagger$ & $\begin{array}{l}\text { Switzerland; commercially available tea fungus beverage } \\
\text { (Kombucha) }\end{array}$ & $\mathrm{A} 22$ & G. intermedius \\
\hline LMG $21312^{\mathrm{T}}\left(=\mathrm{CFN}-\mathrm{Cf} 55^{\mathrm{T}}\right)$ & G. johannae & $\begin{array}{l}\text { 1996; Tapachula Chiapas, Mexico; Coffea arabica L., } \\
\text { rhizosphere }\end{array}$ & A11 & G. johannae \\
\hline LMG 23153 (=CFN-Cf75) & G. johannae & $\begin{array}{l}\text { 1997; Motozintla Chiapas, Mexico; Coffea arabica L., } \\
\text { rhizosphere }\end{array}$ & A11 & G. johannae \\
\hline LMG 23154 (=UAP-Cf76) & G. johannae & $\begin{array}{l}\text { 1997; Motozintla Chiapas, Mexico, Coffea arabica L., } \\
\text { rhizoplane }\end{array}$ & A11 & G. johannae \\
\hline LMG 1348 (=NCIMB 9417=IAM 1836) & G. liquefaciens & 1935; Japan; fruit & A2 & G. liquefaciens \\
\hline LMG $1381^{\mathrm{T}}\left(=\right.$ NCIMB $9136^{\mathrm{T}}=$ NBRC $\left.12388^{\mathrm{T}}\right)$ & G. liquefaciens & 1935; Japan; Diospyros sp., dried fruit & A2 & G. liquefaciens \\
\hline LMG 1509 (=LMD 53.1) & G. liquefaciens & 1950; canal water & A2 & G. liquefaciens \\
\hline LMG $1536^{\mathrm{T}}$ (=NATA-strain $)$ & G. nataicola & $\begin{array}{l}\text { Manila, Philippines; nata de coco; nata producing } \\
\text { organism }\end{array}$ & S7 & G. nataicola \\
\hline LMG $1517(=$ NCIMB 4940=NBRC 14822) & G. oboediens $\dagger$ & & A21 & G. oboediens \\
\hline LMG $1688(=$ LMD 22.3) & G. oboediens $\dagger$ & & A21 & G. oboediens \\
\hline LMG 1689 (=LMD 29.8) & G. oboediens $\dagger$ & & $\mathrm{A} 21$ & G. oboediens \\
\hline LMG $18849^{\mathrm{T}}\left(=\mathrm{LTH} 2460^{\mathrm{T}}\right)$ & G. oboediens & Esslingen, Germany; red wine vinegar fermentation & $\mathrm{A} 21$ & G. oboediens \\
\hline DSM $11826^{\mathrm{T}}\left(=\mathrm{LTH} 2460^{\mathrm{T}}\right)$ & G. oboediens $\dagger$ & Esslingen, Germany; red wine vinegar fermentation & A21 & G. oboediens \\
\hline LMG $18907^{\star}(=\mathrm{JK} 3)$ & G. intermedius $\dagger$ & $\begin{array}{l}\text { 1995; Ljubljana, Slovenia; cider vinegar produced in } \\
\text { submerged bioreactor }\end{array}$ & $\mathrm{A} 21$ & G. oboediens \\
\hline LMG $18908^{\star}(=\mathrm{JKD})$ & G. intermedius $\dagger$ & $\begin{array}{l}\text { 1995; Ljubljana, Slovenia; cider vinegar produced in } \\
\text { submerged bioreactor }\end{array}$ & $\mathrm{A} 21$ & G. oboediens \\
\hline LMG $22126^{\mathrm{T}}\left(=\mathrm{DST}\right.$ GL02 $\left.{ }^{\mathrm{T}}\right)$ & G. rhaeticus & 2003; Val Venosta, South Tyrol, Italy; organic apple juice & S16 & G. rhaeticus \\
\hline LMG $19747^{\mathrm{T}}\left(=\right.$ SRI $\left.1794^{\mathrm{T}}\right)$ & G. sacchari & Australia; Saccharum officinarum, surface microflora & A5 & G. sacchari \\
\hline LMG 19748 (=SRI 1853) & G. sacchari & Queensland Australia; mealy bug & A5 & G. sacchari \\
\hline LMG $1582^{\mathrm{T}}(=\mathrm{LMD} 29.3)$ & G. saccharivorans & 1927; Germany; beet juice & $\mathrm{A} 23$ & G. saccharivorans \\
\hline LMG 1584 (=LMD 39.5) & G. saccharivorans & & $\mathrm{A} 23$ & G. saccharivorans \\
\hline LMG $22125^{\mathrm{T}}\left(=\mathrm{DST}\right.$ GL01 $\left.{ }^{\mathrm{T}}\right)$ & G. swingsii & 2003; Val Venosta, South Tyrol, Italy; organic apple juice & S4 & G. swingsii \\
\hline LMG $1515^{\mathrm{T}}\left(=\right.$ NCIMB $\left.11664^{\mathrm{T}}=\mathrm{JCM} 7644^{\mathrm{T}}\right)$ & G. xylinus & Mountain ash berries & $\mathrm{A} 14$ & G. xylinus \\
\hline LMG 1518 (=NCIMB 5346) & G. europaeus & O. Verona & A14 & G. xylinus \\
\hline LMG $1356^{\mathrm{T}}\left(=\right.$ NBRC $\left.3250^{\mathrm{T}}\right)$ & Gl. albidus & 1941; Japan; Dahlia coccinea; A. albidus & A8 & Gl. albidus \\
\hline LMG 1375 t1 (=NBRC 3273) & Gl. albidus & 1941; Nishinomiya, Japan; Myrica rubra, fruit & A8 & Gl. albidus \\
\hline LMG $1368^{\mathrm{T}}\left(=\right.$ NBRC $\left.3267^{\mathrm{T}}\right)$ & Gl. cerinus & 1941; Osaka, Japan; Prunus sp. (cherry) & A19 & Gl. cerinus \\
\hline
\end{tabular}


Table 1. cont.

\begin{tabular}{|c|c|c|c|c|}
\hline Strain numbers & $\begin{array}{l}\text { Species designation at the } \\
\text { time of selection }\end{array}$ & Year, place and source of isolation & AFLP group & $\begin{array}{l}\text { Proposed species } \\
\text { designation }\end{array}$ \\
\hline LMG 1376 t1 (=NBRC 3274) & Gl. cerinus & 1941; Nishinomiya, Japan; Myrica rubra, fruit. & A19 & Gl. cerinus \\
\hline LMG 1389 (=NBRC 3275) & Gl. cerinus & $\begin{array}{l}\text { 1941; herbal garden, Kyoto, Japan; Rheum rhabarbarum, } \\
\text { flower }\end{array}$ & A19 & Gl. cerinus \\
\hline LMG 1390 (=NBRC 3276) & Gl. cerinus & $\begin{array}{l}\text { 1941; herbal garden, Kyoto, Japan; Rheum rhabarbarum, } \\
\text { flower; type strain of Gl. asaii }\end{array}$ & A19 & Gl. cerinus \\
\hline LMG 1357 t1 (=NBRC 3251) & Gl. frateuri & 1941; botanical garden, Kyoto, Japan; Dahlia sp., flower & A18 & Gl. frateuri \\
\hline LMG 1358 (=NBRC 3253) & Gl. frateuri & 1941; botanical garden, Kyoto, Japan; Dahlia sp., flower & A18 & Gl. frateuri \\
\hline LMG $1365^{\mathrm{T}}\left(=\right.$ NBRC $\left.2364^{\mathrm{T}}\right)$ & Gl. frateuri & 1941; Osaka, Japan; Fragaria ananassa & $\mathrm{A} 18$ & Gl. frateuri \\
\hline LMG 1369 t1 (=NBRC 3268) & Gl. frateuri & 1941; Osaka, Japan; Prunus sp. (cherry) & A18 & Gl. frateuri \\
\hline LMG 1371 (=NBRC 3270) & Gl. frateuri & 1941; Osaka, Japan; Prunus sp. (cherry) & A18 & Gl. frateuri \\
\hline LMG $1379(=$ NBRC 3286) & Gl. frateuri & 1941; Osaka, Japan; Eriobotrya japonica, fruit & $\mathrm{A} 18$ & Gl. frateuri \\
\hline LMG $1367^{\mathrm{T}} \mathrm{t} 1(=\mathrm{NBRC} 2366)$ & Gl. kondonii & 1941; Osaka, Japan; Fragaria ananassa & S3 & Gl. kondonii \\
\hline LMG 1359 (=NBRC 3462) & Gl. oxydans & & A10 & Gl. oxydans \\
\hline LMG 1385 (=NBRC 3293) & Gl. oxydans & 1941; Osaka, Japan; Diospyros sp., dried fruit & $\mathrm{A} 10$ & Gl. oxydans \\
\hline LMG 1393 (=NBRC 12528) & Gl. oxydans & $\begin{array}{l}\text { Delft, Netherlands; Amstel beer; assay of nicotinic acid } \\
\text { (= niacin), p-aminobenzoic acid, pantothenic acid; } \\
\text { type strain of Gl. oxydans subsp. suboxydans }\end{array}$ & A 10 & Gl. oxydans \\
\hline LMG 1395 (=NBRC 3287) & Gl. oxydans & $\begin{array}{l}\text { 1941; botanical garden, Kyoto, Japan; Liatris scariosa; } \\
\text { flower }\end{array}$ & A10 & Gl. oxydans \\
\hline LMG $1396^{*}$ & Gl. oxydans & Beer & A10 & Gl. oxydans \\
\hline LMG $1408^{\mathrm{T}}\left(=\right.$ NBRC $\left.14819^{\mathrm{T}}\right)$ & Gl. oxydans & Beer & $\mathrm{A} 10$ & Gl. oxydans \\
\hline LMG 1424 (=NBRC 3244) & Gl. oxydans & & A10 & Gl. oxydans \\
\hline LMG $1674^{\star}$ & Gl. oxydans & 1924; Delft, Netherlands; beer & $\mathrm{A} 10$ & Gl. oxydans \\
\hline LMG 1486 (=NBRC 3254) & Gl. thailandicus & 1941; Osaka, Japan; Fragaria ananassa & $\mathrm{A} 17$ & Gl. thailandicus \\
\hline LMG 1487 (=NBRC 3255) & Gl. thailandicus & 1941; Osaka, Japan; Fragaria ananassa & A17 & Gl. thailandicus \\
\hline LMG $23137^{\mathrm{T}}\left(=\mathrm{F} 149-1^{\mathrm{T}}\right)$ & Gl. thailandicus & $\begin{array}{l}\text { Bangkok, Thailand; Indian cork tree (Millingtonia } \\
\text { hortensis), flower }\end{array}$ & A17 & Gl. thailandicus \\
\hline LMG $23138(=$ F142-1) & Gl. thailandicus & Bangkok, Thailand; glossy ixora (Ixora lobbii), flower & A17 & Gl. thailandicus \\
\hline DSM $17861^{\mathrm{T}}\left(=\mathrm{CDGNIH}^{\mathrm{T}}\right)$ & Gr. bethesdensis & $\begin{array}{l}\text { 2003; Bethesda, United States; patient with chronic } \\
\text { granulomatous disease, lymph node }\end{array}$ & S9 & Gr. bethesdensis \\
\hline LMG $21812^{\mathrm{T}}\left(=\right.$ Yo- $\left.3^{\mathrm{T}}\right)$ & K. baliensis & 1996; Bali, Indonesia; palm brown sugar & S11 & K. baliensis \\
\hline LMG $24037^{\mathrm{T}}\left(=\mathrm{AC} 28^{\mathrm{T}}\right)$ & N. chiangmaiensis & $\begin{array}{l}\text { 2002; Chiang-Mai, Thailand; red ginger (Alpinia pur- } \\
\text { purata), flower }\end{array}$ & S2 & N. chiangmaiensis \\
\hline LMG $23170^{\mathrm{T}}\left(=\mathrm{S}-877^{\mathrm{T}}\right)$ & S. floricola & Kanagawa Prefecture, Japan; pollen & S14 & S. floricola \\
\hline LMG $21291^{\mathrm{T}}\left(=\mathrm{PA}^{\mathrm{T}} 1^{\mathrm{T}}\right)$ & Sw. salitolerans & $\begin{array}{l}\text { 1998; Pichavaram mangrove forest Chidambaram, } \\
\text { Tamil Nadu, India; wild rice Porteresia coarctata }\end{array}$ & S1 & Sw. salitolerans \\
\hline
\end{tabular}

*Strain for which no DNA-DNA hybridization data or 16S-23S rRNA gene ITS sequence analysis data have (previously) been reported.

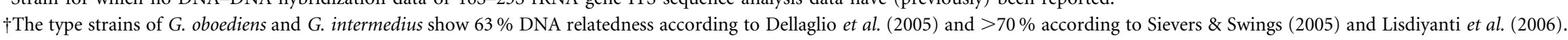


using the primers ${ }^{\star} \mathrm{Gamma},{ }^{\star} \mathrm{PD},{ }^{\star} \mathrm{O},{ }^{\star} 3,{ }^{\star} \mathrm{R}, \mathrm{pA}, \mathrm{Gamma}$, 3 and BKL1 (Coenye et al., 1999; Cleenwerck et al., 2007). This revealed that Gluconacetobacter kombuchae $\mathrm{RG}^{\mathrm{T}}$ (AY688433) was its nearest neighbour [AY688433, 99.6\% 16S rRNA gene sequence similarity as calculated with the BioNumerics 4.61 software package (Applied Maths) using an open gap penalty of $100 \%$ and a unit gap penalty of $0 \%$ ], indicating that strain LMG $23726^{\mathrm{T}}$ is a subculture of RG3 $^{\mathrm{T}}$. Secondly, DNA-DNA hybridizations between Gluconacetobacter kombuchae LMG $23726^{\mathrm{T}}$ and Gluconacetobacter hansenii LMG $1527^{\mathrm{T}}$ revealed a DNA relatedness value of $81 \%$ in the present study, which is clearly above the $70 \%$ threshold (Wayne et al., 1987; Stackebrandt et al., 2002) and much higher than the $25 \%$ DNA relatedness reported by Dutta \& Gachhui (2007). Phylogenetically, Gluconacetobacter kombuchae and Gluconacetobacter hansenii belong to the Gluconacetobacter xylinus branch (Dutta \& Gachhui, 2007; Yamada \& Yukphan, 2008), which contains several species showing $\geqslant 99.4 \%$ 16S rRNA gene sequence similarity. DNA relatedness values between closely related species of this cluster are generally intermediate (see Supplementary Table S2). Thirdly, the G $+\mathrm{C}$ content of DNA prepared for DNA-DNA hybridization was determined for both strains by HPLC according to the method of Mesbah et al. (1989) and was $59.4 \mathrm{~mol} \%$ for LMG $1527^{\mathrm{T}}$ and $59.5 \mathrm{~mol} \%$ for LMG $23726^{\mathrm{T}}$, the latter being definitely higher than the $55.8 \mathrm{~mol} \%$ value reported by Dutta \& Gachhui (2007). Fourthly, the species description of Gluconacetobacter hansenii was emended recently by Lisdiyanti et al. (2006); among ten strains previously assigned to this species, only three strains were shown to actually be members of the species (Lisdiyanti et al., 2006). These three strains (LMG 1524, LMG $1527^{\mathrm{T}}$ and LMG 1528 ) as well as Gluconacetobacter kombuchae LMG $23726^{\mathrm{T}}$, were investigated for the phenotypic characteristics that have been reported to enable differentiation of both these species from the other species of the Gluconacetobacter xylinus branch. The production of 2-keto-D-gluconic acid and 5-keto-D-gluconic acid from D-glucose was determined by the method described by Gosselé et al. (1980) using high pressure anion-exchange chromatography with conductivity detection under ion suppression (Van der Meulen et al., 2006) instead of TLC. Growth on the carbon sources ethanol, sucrose, sorbitol and D-mannitol; growth in the presence of $30 \%$ D-glucose; production of acid from galactitol, and production of cellulose were examined by previously reported methods (Cleenwerck et al., 2002; Lisdiyanti et al., 2006). All four strains produced 2-ketoand 5-keto-D-gluconic acid from D-glucose, produced acid from galactitol and were able to grow on D-sorbitol and Dmannitol as energy sources. Growth on the energy sources ethanol and sucrose was variable (LMG $1527^{\mathrm{T}}$ grew weakly on ethanol, but not on sucrose), as well as growth in the presence of $30 \%$ D-glucose (LMG $1527^{\mathrm{T}}$ grew weakly in $30 \%$ D-glucose). Cellulose production was clearly noticed for LMG $23726^{\mathrm{T}}$, but could not be confirmed for LMG 1524. In general, most previous phenotypic findings were confirmed. Fifthly, according to Dutta \& Gachhui (2007), the major difference between the type strain of Gluconacetobacter kombuchae and related gluconacetobacters was its ability to fix nitrogen. These authors confirmed the presence of the nifH gene in Gluconacetobacter kombuchae by PCR with the degenerate primers $19 \mathrm{~F}$ and 407R (Franke et al., 1998) and sequencing of the amplified PCR product (Dutta \& Gachhui, 2007). In this study, the four strains all generated a PCR product of the same size ( $\sim 600 \mathrm{bp})$ using the degenerate primers used by Dutta \& Gachhui (2007) (data not shown), indicating the presence of the nifH gene in all of these strains. The data presented clearly show that Gluconacetobacter kombuchae is a later heterotypic synonym of Gluconacetobacter hansenii, with the name Gluconacetobacter hansenii having priority over the name Gluconacetobacter kombuchae according to Rules 38 and 42 of the Bacteriological Code (Lapage et al., 1992).

Strain LMG 1547 (A30) was classified as Acetobacter pasteurianus by Gosselé et al. (1983) based on its position in subphenon $\mathrm{E}$, established on the basis of numerical analysis of 177 phenotypic features. Its AFLP DNA fingerprint showed considerable resemblance $(\sim 55 \%$ band pattern similarity and clear visual similarity) to that of Acetobacter orientalis LMG $21417^{\mathrm{T}}$. DNA hybridizations between both strains revealed $100 \%$ DNA relatedness, proving that strain LMG 1547 is in fact a member of Acetobacter orientalis.

Strains LMG 18907 and LMG 18908 (A21) were classified as Gluconacetobacter intermedius on the basis of SDS-PAGE data of their soluble proteins (Boesch et al., 1998). However, their AFLP DNA fingerprints showed more similarity with the AFLP patterns of strains of Gluconacetobacter oboediens. At present, confusion exists concerning the taxonomic status of Gluconacetobacter oboediens and Gluconacetobacter intermedius, due to discrepancies in the DNA relatedness values reported for their type strains (Cleenwerck \& De Vos, 2008). Gluconacetobacter oboediens and Gluconacetobacter intermedius were described around the same time in the same year (Boesch et al., 1998; Sokollek et al., 1998) and were hence not compared with each other upon description. Later studies revealed that they were phylogenetically closely related species of the Gluconacetobacter xylinus branch (Dellaglio et al., 2005; Lisdiyanti et al., 2006; Yamada \& Yukphan, 2008). According to Sievers \& Swings (2005) and Lisdiyanti et al. (2006), the names should be regarded as synonymous, mainly because a high DNA relatedness value was found between their type strains (76\% and $>77 \%$, respectively). However, according to Dellaglio et al. (2005), the type strains shared $63 \%$ DNA relatedness, which was somewhat lower than the $68 \%$ DNA relatedness observed between Gluconacetobacter oboediens LMG $18849^{\mathrm{T}}$ and Gluconacetobacter europaeus LMG $18890^{\mathrm{T}}$ (see Supplementary Table S2), suggesting that both species should remain separate. The AFLP DNA fingerprint data supported the conclusion based on the DNA relatedness of $63 \%$ between the type strains. In this 
study, additional tests were therefore performed to clarify the taxonomic status of both species. Firstly, Gluconacetobacter intermedius DSM $11804^{\mathrm{T}}$ and Gluconacetobacter oboediens DSM $11826^{\mathrm{T}}$, used in the hybridization study of Lisdiyanti et al. (2006), were analysed by AFLP and their patterns were found to cluster with those of Gluconacetobacter intermedius LMG $18909^{\mathrm{T}}$ and Gluconacetobacter oboediens LMG $18849^{\mathrm{T}}$, respectively, with a similarity higher than the reproducibility level. Secondly, the strains of the species of the Gluconacetobacter xylinus branch were subjected to (GTG) ${ }_{5}$-PCR DNA fingerprinting following a previously described protocol (De Vuyst et al., 2008). Clustering of the $(\mathrm{GTG})_{5}$ DNA fingerprints (Supplementary Fig. S1) revealed the same groupings as AFLP DNA fingerprinting. Thirdly, additional DNA-DNA hybridizations with strains LMG $18849^{\mathrm{T}}$, LMG 1517, LMG 1688 and LMG 1619 (A21) and LMG $18909^{\mathrm{T}}$ (A22) revealed DNA relatedness values ranging from 53 to $63 \%$ between Gluconacetobacter intermedius LMG $18909^{\mathrm{T}}$ and strains of AFLP group A21, containing the type strain of Gluconacetobacter oboediens, whereas values ranging from 68 to $100 \%$ were obtained between strains of AFLP group A21 (Supplementary Table S2). Together, the data support the conclusion that Gluconacetobacter intermedius and Gluconacetobacter oboediens should not be regarded as synonymous. Consequently, strains LMG 18907 and LMG 18908 should be reclassified as members of the species Gluconacetobacter oboediens. Interestingly, the type strain of Gluconacetobacter intermedius was isolated from Kombucha, whereas the strains of AFLP cluster A21 with a known origin, were isolated from vinegar.

Strain LMG 1521 (A16) was classified as Acetobacter xylinus (=Gluconacetobacter xylinus) on the basis of phenotypic data (Gosselé et al., 1983). However Boesch et al. (1998) noticed that this strain reacted with the oligonucleotide probe 23seu, developed for Gluconacetobacter europaeus. The AFLP data confirm its classification as Gluconacetobacter europaeus.

It is clear from the results presented above that AFLP DNA fingerprinting enables the accurate identification and classification of a broad range of $\mathrm{AAB}$ at the species level. Besides this, AFLP analyses appear to be useful for the determination of genetic diversity amongst strains of the same species. In Fig. 1 it can be noticed that the AFLP patterns of strains belonging to a particular species and containing more than 40 bands generally group at a linkage level of $50 \%$ or more. Those with fewer bands generally cluster at a lower linkage level, as can be seen for several species of the genus Acetobacter, with three of them being split up in several AFLP groups. Also, Janssen et al. (1996) noticed that the linkage levels of some clusters dropped significantly if the number of bands in the AFLP patterns decreased. These data indicate that AFLP DNA fingerprints with less than 40 bands are more discriminatory at the intraspecies level and are less suitable for species-level identification.

Nevertheless, some conclusions regarding the intraspecific genetic diversity can be made from the data reported. For instance, several species, such as Gluconacetobacter oxydans (A10), Acetobacter pasteurianus (A13, A33), Gluconacetobacter frateurii (A18), Gluconacetobacter cerinus (A19), Acetobacter indonesienis (S12, A32) and Acetobacter cerevisiae (A25, A29, S20) harbour genetically diverse strains, whereas other species, such as Gluconacetobacter diazotrophicus (A3), Acetobacter krungthepensis (A7), Gluconacetobacter albidus (A8), Gluconacetobacter azotocaptans (A9), Gluconacetobacter johannae (A11), Acetobacter aceti (A12), Acetobacter estunensis (A15), Gluconacetobacter thailandicus (A17) and Gluconacetobacter hansenii (A20), harbour strains that generate quite homogeneous AFLP patterns. For the Gluconobacter strains, the AFLP data correlate very well with the results of Takahashi et al. (2006) based on 16S$23 \mathrm{~S}$ rRNA gene spacer region sequence analysis data. For the species appearing to have a limited genetic diversity, AFLP analyses of additional strains (if available) and with other primer combinations (such as A01/T03) are advised to gain a deeper understanding of their genetic diversity. A previous study showed that a better insight into the genetic diversity of Gluconacetobacter diazotrophicus was obtained when more isolates from sugar cane, as well as from other host plants such as sweet potato and from the mealybug, Saccharococcus sacchari, were investigated (Caballero-Mellado et al., 1995). Other studies have stated that highly related strains may be distinguished by AFLP when the appropriate set of selective primers is used (e.g. Janssen et al., 1996).

This study further revealed strains with very similar AFLP DNA fingerprints, grouping together at a linkage level of $80 \%$ or more, e.g. Gluconacetobacter liquefaciens LMG $1381^{\mathrm{T}}$ and LMG 1348 (A2). These strains may be clonally related, especially if they were isolated from the same source at the same site in the same year. In this perspective, it is interesting to note that the four Gluconacetobacter thailandicus strains (A17) that showed very similar AFLP patterns had different geographical origins. Two strains were recently isolated from flowers collected in Thailand (LMG $23137^{\mathrm{T}}$ and LMG 23138), whereas the other two strains were isolated in 1941 from Fragaria ananassa in Japan (LMG 1486 and LMG 1487). For all these strains, additional analyses, such as AFLP using other primer combinations or PFGE, are needed to determine whether these strains are indeed clonally related.

In conclusion, the data in this study demonstrate that AFLP DNA fingerprinting permits the accurate identification and classification of a broad range of $A A B$ at the species level. In addition, AFLP DNA fingerprinting appears to be useful for determining intraspecific genetic diversity. The technique can be regarded as valuable for the taxonomy of AAB. 


\section{Acknowledgements}

This research was funded by the Federal Research Policy (Action for the promotion of and co-operation with the Belgian Coordinated Collections of Microorganisms, BCCM) and the Research Council of the Vrije Universiteit Brussel. The authors wish to acknowledge Katrien Vandemeulebroecke, Leentje Christiaens, Katrien Engelbeen and Cindy Snauwaert for their technical support.

\section{References}

Boesch, C., Trček, J., Sievers, M. \& Teuber, M. (1998). Acetobacter intermedius sp. nov. Syst Appl Microbiol 21, 220-229.

Brady, C., Venter, S., Cleenwerck, I., Vancanneyt, M., Swings, J. \& Coutinho, T. (2007). A FAFLP system for the improved identification of plant-pathogenic and plant-associated species of the genus Pantoea. Syst Appl Microbiol 30, 413-417.

Caballero-Mellado, J., Fuentes-Ramírez, L. E., Reis, V. M. \& Martinez-Romero, E. (1995). Genetic structure of Acetobacter diazotrophicus populations and identification of a new genetically distant group. Appl Environ Microbiol 61, 3008-3013.

Camu, N., De Winter, T., Verbrugghe, K., Cleenwerck, I., Vandamme, P., Takrama, J. S., Vancanneyt, M. \& De Vuyst, L. (2007). Dynamics and biodiversity of populations of lactic acid bacteria and acetic acid bacteria involved in spontaneous heap fermentation of cocoa beans in Ghana. Appl Environ Microbiol 73, 1809-1824.

Cleenwerck, I. \& De Vos, P. (2008). Polyphasic taxonomy of acetic acid bacteria: an overview of the currently applied methodology. Int $J$ Food Microbiol 125, 2-14.

Cleenwerck, I., Vandemeulebroecke, K., Janssens, D. \& Swings, J. (2002). Re-examination of the genus Acetobacter, with descriptions of Acetobacter cerevisiae sp. nov. and Acetobacter malorum sp. nov. Int J Syst Evol Microbiol 52, 1551-1558.

Cleenwerck, I., Camu, N., Engelbeen, K., De Winter, T., Vandemeulebroecke, K., De Vos, P. \& De Vuyst, L. (2007). Acetobacter ghanensis sp. nov., a novel acetic acid bacterium isolated from traditional heap fermentations of Ghanaian cocoa beans. Int $J$ Syst Evol Microbiol 57, 1647-1652.

Cleenwerck, I., González, Á., Camu, N., Engelbeen, K., De Vos, P. \& De Vuyst, L. (2008). Acetobacter fabarum sp. nov., a Ghanaian cocoa bean heap fermentation acetic acid bacterium. Int J Syst Evol Microbiol 58, 2180-2185.

Coenye, T., Falsen, E., Vancanneyt, M., Hoste, B., Govan, J. R. W., Kersters, K. \& Vandamme, P. (1999). Classification of Alcaligenes faecalis-like isolates from the environment and human clinical samples as Ralstonia gilardii sp. nov. Int J Syst Bacteriol 49, 405-413.

Dellaglio, F., Cleenwerck, I., Felis, G. E., Engelbeen, K., Janssens, D. \& Marzotto, M. (2005). Description of Gluconacetobacter swingsii sp. nov. and Gluconacetobacter rhaeticus sp. nov., isolated from Italian apple fruit. Int J Syst Evol Microbiol 55, 2365-2370.

De Vuyst, L., Camu, N., De Winter, T., Vandemeulebroecke, K., Van de Perre, V., Vancanneyt, M., De Vos, P. \& Cleenwerck, I. (2008). Validation of the (GTG) $)_{5}$-rep-PCR fingerprinting technique for rapid classification and identification of acetic acid bacteria, with a focus on isolates from Ghanaian fermented cocoa beans. Int J Food Microbiol 125, 79-90.

Dutta, D. \& Gachhui, R. (2006). Novel nitrogen-fixing Acetobacter nitrogenifigens sp. nov., isolated from Kombucha tea. Int J Syst Evol Microbiol 56, 1899-1903.

Dutta, D. \& Gachhui, R. (2007). Nitrogen-fixing and celluloseproducing Gluconacetobacter kombuchae sp. nov., isolated from Kombucha tea. Int J Syst Evol Microbiol 57, 353-357.
Ezaki, T., Hashimoto, Y. \& Yabuuchi, E. (1989). Fluorometric deoxyribonucleic acid-deoxyribonucleic acid hybridization in microdilution wells as an alternative to membrane filter hybridization in which radioisotopes are used to determine genetic relatedness among bacterial strains. Int J Syst Bacteriol 39, 224-229.

Franke, I. H., Fegan, M., Hayward, C. \& Sly, L. I. (1998). Nucleotide sequence of the nifH gene coding for nitrogen reductase in the acetic acid bacterium Acetobacter diazotrophicus. Lett Appl Microbiol 26, 12 16.

Franke, I. H., Fegan, M., Hayward, C., Leonard, G., Stackebrandt, E. \& Sly, L. I. (1999). Description of Gluconacetobacter sacchari sp. nov., a new species of acetic acid bacterium isolated from the leaf sheath of sugar cane and from the pink sugar-cane mealy bug. Int J Syst Bacteriol 49, 1681-1693.

Franz, C. M. A. P., Vancanneyt, M., Vandemeulebroecke, K., De Wachter, M., Cleenwerck, I., Hoste, B., Schillinger, U., Holzapfel, W. H. \& Swings, J. (2006). Pediococcus stilesii sp. nov., isolated from maize grains. Int J Syst Evol Microbiol 56, 329-333.

Fuentes-Ramírez, L. E., Bustillos-Cristales, R., Tapia-Hernandez, A., Jimenez-Salgado, T., Wang, E. T., Martinez-Romero, E. \& CaballeroMellado, J. (2001). Novel nitrogen-fixing acetic acid bacteria, Gluconacetobacter johannae sp. nov. and Gluconacetobacter azotocaptans sp. nov., associated with coffee plants. Int J Syst Evol Microbiol 51, 1305-1314.

Goris, J., Suzuki, K., De Vos, P., Nakase, T. \& Kersters, K. (1998). Evaluation of a microplate DNA-DNA hybridization method compared with the initial renaturation method. Can J Microbiol 44, $1148-1153$.

Gosselé, F., Swings, J. \& De Ley, J. (1980). A rapid, simple and simultaneous detection of 2-keto, 5-keto- and 2,5-diketogluconic acids by thin-layer chromatography in culture media of acetic acid bacteria. Zentralbl Bakteriol Parasitenkd Infektionskr Hyg Abt 1 Orig C1, 178-181.

Gosselé, F., Swings, J., Kersters, K., Pauwels, P. \& De Ley, J. (1983). Numerical analysis of phenotypic features and protein gel electropherograms of a wide variety of Acetobacter strains. Proposal for the improvement of the taxonomy of the genus Acetobacter Beijerinck 1898, 215. Syst Appl Microbiol 4, 338-368.

Greenberg, D. E., Porcella, S. F., Stock, F., Wong, A., Conville, P. S., Murray, P. R., Holland, S. M. \& Zelazny, A. M. (2006). Granulibacter bethesdensis gen. nov., sp. nov., a distinctive pathogenic acetic acid bacterium in the family Acetobacteraceae. Int J Syst Evol Microbiol 56, 2609-2616.

Janssen, P., Coopman, R., Huys, G., Swings, J., Bleeker, M., Vos, P., Zabeau, M. \& Kersters, K. (1996). Evaluation of the DNA fingerprinting method AFLP as a new tool in bacterial taxonomy. Microbiology 142, 1881-1893.

Jojima, Y., Mihara, Y., Suzuki, S., Yokozeki, K., Yamanaka, S. \& Fudou, R. (2004). Saccharibacter floricola gen. nov., sp. nov., a novel osmophilic acetic acid bacterium isolated from pollen. Int J Syst Evol Microbiol 54, 2263-2267.

Katsura, K., Kawasaki, H., Potacharoen, W., Saono, S., Seki, T., Yamada, Y., Uchimura, T. \& Komagata, K. (2001). Asaia siamensis sp. nov., an acetic acid bacterium in the $\alpha$-Proteobacteria. Int J Syst Evol Microbiol 51, 559-563.

Kersters, K., Lisdiyanti, P., Komagata, K. \& Swings, J. (2006). The family Acetobacteraceae: the genera Acetobacter, Acidomonas, Asaia, Gluconacetobacter, Gluconobacter, and Kozakia. In The Prokaryotes, 3rd edn, vol. 5, pp. 163-200. Edited by M. Dworkin, S. Falkow, E. Rosenberg, K.-H. Schleifer \& E. Stackebrandt. New York: SpringerVerlag.

Lapage, S. P., Sneath, P. H. A., Lessel, E. F., Skerman, V. B. D., Seeliger, H. P. R. \& Clark, W. A. (editors) (1992). International Code 
of Nomenclature of Bacteria (1990 Revision). Bacteriological Code. Washington, DC: American Society for Microbiology.

Lisdiyanti, P., Kawasaki, H., Seki, T., Yamada, Y., Uchimura, T. \& Komagata, K. (2000). Systematic study of the genus Acetobacter with descriptions of Acetobacter indonesiensis sp. nov., Acetobacter tropicalis sp. nov., Acetobacter orleanensis (Henneberg 1906) comb. nov., Acetobacter lovaniensis (Frateur 1950) comb. nov., and Acetobacter estunensis (Carr 1958) comb. nov. J Gen Appl Microbiol 46, 147-165.

Lisdiyanti, P., Kawasaki, H., Seki, T., Yamada, Y., Uchimura, T. \& Komagata, K. (2001). Identification of Acetobacter strains isolated from Indonesian sources, and proposals of Acetobacter syzygii sp. nov., Acetobacter cibinongensis sp. nov., and Acetobacter orientalis sp. nov. J Gen Appl Microbiol 47, 119-131.

Lisdiyanti, P., Kawasaki, H., Widyastuti, Y., Saono, S., Seki, T., Yamada, Y., Uchimura, T. \& Komagata, K. (2002). Kozakia baliensis gen. nov., sp. nov., a novel acetic acid bacterium in the $\alpha$ Proteobacteria. Int J Syst Evol Microbiol 52, 813-818.

Lisdiyanti, P., Navarro, R. R., Uchimura, T. \& Komagata, K. (2006). Reclassification of Gluconacetobacter hansenii strains and proposals of Gluconacetobacter saccharivorans sp. nov. and Gluconacetobacter nataicola sp. nov. Int J Syst Evol Microbiol 56, 2101-2111.

Loganathan, P. \& Nair, S. (2004). Swaminathania salitorans gen. nov., sp. nov., a salt-tolerant, nitrogen-fixing and phosphate-solubilizing bacterium from wild rice (Porteresia coarctata Tateoka). Int J Syst Evol Microbiol 54, 1185-1190.

Malimas, T., Yukphan, P., Takahashi, M., Kaneyasu, M., Potacharoen, W., Tanasupawat, S., Nakagawa, Y., Tanticharoen, M. \& Yamada, Y. (2007). Gluconobacter kondonii sp. nov., an acetic acid bacterium in the $\alpha$-Proteobacteria. J Gen Appl Microbiol 53, 301-307.

Malimas, T., Yukphan, P., Takahashi, M., Kaneyasu, M., Potacharoen, W., Tanasupawat, S., Nakagawa, Y., Tanticharoen, M. \& Yamada, Y. (2008a). Asaia lannaensis sp. nov., a new acetic acid bacterium in the Alphaproteobacteria. Biosci Biotechnol Biochem 72, 666-671.

Malimas, T., Yukphan, P., Takahashi, M., Muramatsu, Y., Kaneyasu, M., Potacharoen, W., Tanasupawat, S., Nakagawa, Y., Tanticharoen, M. \& Yamada, Y. (2008b). Gluconobacter roseus (ex Asai 1935) sp. nov., nom. rev., a pink-colored acetic acid bacterium in the Alphaproteobacteria. $J$ Gen Appl Microbiol 54, 119-125.

Mesbah, M., Premachandran, U. \& Whitman, W. B. (1989). Precise measurement of the $\mathrm{G}+\mathrm{C}$ content of deoxyribonucleic acid by highperformance liquid chromatography. Int J Syst Bacteriol 39, 159-167.

Moore, J. E., Mc Calmont, M., Xu, J., Millar, B. C. \& Heaney, N. (2002). Asaia sp., an unusual spoilage organism of fruit-flavored bottled water. Appl Environ Microbiol 68, 4130-4131.

Muthukumarasamy, R., Cleenwerck, I., Revathi, G., Vadivelu, M., Janssens, D., Hoste, B., Gum, K. U., Park, K.-D., Son, C. Y. \& other authors (2005). Natural association of Gluconacetobacter diazotrophicus and diazotrophic Acetobacter peroxydans with wetland rice. Syst Appl Microbiol 28, 277-286.

Navarro, R. R., Uchimura, T. \& Komagata, K. (1999). Taxonomic heterogeneity of strains comprising Gluconacetobacter hansenii. J Gen Appl Microbiol 45, 295-300.

Ndoye, B., Cleenwerck, I., Engelbeen, K., Dubois-Dauphin, R., Guiro, A. T., Van Trappen, S., Willems, A. \& Thonart, P. (2007). Acetobacter senegalensis sp. nov., a thermotolerant acetic acid bacterium isolated in Senegal (sub-Saharan Africa) from mango fruit (Mangifera indica L.). Int J Syst Evol Microbiol 57, 1576-1581.

On, S. L. W., Harrington, C. S. \& Atabay, H. I. (2003). Differentiation of Arcobacter species by numerical analysis of AFLP profiles and description of a novel Arcobacter from pig abortions and turkey faeces. J Appl Microbiol 95, 1096-1105.
Savelkoul, P. H., Aarts, H. J., de Haas, J., Dijkshoorn, L., Duim, B., Otsen, M., Rademaker, J. L., Schouls, L. \& Lenstra, J. A. (1999). Amplified-fragment length polymorphism analysis: the state of the art. J Clin Microbiol 37, 3083-3091.

Schüller, G., Hertel, C. \& Hammes, W. P. (2000). Gluconacetobacter entanii sp. nov., isolated from submerged high-acid industrial vinegar fermentations. Int J Syst Evol Microbiol 50, 2013-2020.

Sievers, M. \& Swings, J. (2005). Family Acetobacteraceae. In Bergey's Manual of Systematic Bacteriology, 2nd edn, vol. 2, pp. 41-95. Edited by G. M. Garrity. New York: Springer.

Sievers, M., Sellmer, S. \& Teuber, M. (1992). Acetobacter europaeus sp. nov., a main component of industrial vinegar fermenters in Central Europe. Syst Appl Microbiol 15, 386-392.

Silva, L. R., Cleenwerck, I., Rivas, R., Swings, J., Trujillo, M. E., Willems, A. \& Velázquez, E. (2006). Acetobacter oeni sp. nov., isolated from spoiled red wine. Int J Syst Evol Microbiol 56, 21-24.

Sokollek, S. J., Hertel, C. \& Hammes, W. P. (1998). Description of Acetobacter oboediens sp. nov. and Acetobacter pomorum sp. nov., two new species isolated from industrial vinegar fermentations. Int J Syst Bacteriol 48, 935-940.

Stackebrandt, E., Frederiksen, W., Garrity, G. M., Grimont, P. A. D., Kämpfer, P., Maiden, M. C. J., Nesme, X., Rosselló-Mora, R., Swings, J. \& other authors (2002). Report of the ad hoc committee for the reevaluation of the species definition in bacteriology. Int J Syst Evol Microbiol 52, 1043-1047.

Takahashi, M., Yukphan, P., Yamada, Y., Suzuki, K., Sakane, T. \& Nakagawa, Y. (2006). Intrageneric structure of the genus Gluconobacter analyzed by the 16S rRNA gene and 16S-23S rRNA gene internal transcribed spacer sequences. J Gen Appl Microbiol 52, 187-193.

Thompson, F. L., Hoste, B., Vandemeulebroecke, K. \& Swings, J. (2001). Genomic diversity amongst Vibrio isolates from different source determined by fluorescent amplified fragment length polymorphism. Syst Appl Microbiol 24, 520-538.

Trček, J. \& Teuber, M. (2002). Genetic and restriction analysis of the 16S-23S rDNA internal transcribed spacer regions of the acetic acid bacteria. FEMS Microbiol Lett 208, 69-75.

Tuuminen, T., Heinäsmäki, T. \& Kerttula, T. (2006). First report of bacteremia by Asaia bogorensis, in a patient with a history of intravenous-drug abuse. J Clin Microbiol 44, 3048-3050.

Tuuminen, T., Roggenkamp, A. \& Vuopio-Varkila, J. (2007). Comparison of two bacteremic Asaia bogorensis isolates from Europe. Eur J Clin Microbiol Infect Dis 26, 523-524.

Urakami, T., Tamaoka, J., Suzuki, K.-I. \& Komagata, K. (1989). Acidomonas gen. nov., incorporating Acetobacter methanolicus as Acidomonas methanolica comb. nov. Int J Syst Bacteriol 39, 50-55.

Van der Meulen, R., Adriany, T., Verbrugghe, K. \& De Vuyst, L. (2006). Kinetic analysis of bifidobacterial metabolism reveals a minor role for succinic acid in the regeneration of $\mathrm{NAD}^{+}$through its growth-associated production. Appl Environ Microbiol 72, 5204-5210.

Wayne, L. G., Brenner, D. J., Colwell, R. R., Grimont, P. A. D., Kandler, O., Krichevsky, M. I., Moore, L. H., Moore, W. E. C., Murray, R. G. E. \& other authors (1987). International Committee on Systematic Bacteriology. Report of the ad hoc committee on reconciliation of approaches to bacterial systematics. Int J Syst Bacteriol 37, 463-464.

Willems, A., Coopman, R. \& Gillis, M. (2001). Comparison of sequence analysis of 16S-23S rDNA spacer regions, AFLP analysis and DNA-DNA hybridizations in Bradyrhizobium. Int J Syst Evol Microbiol 51, 623-632.

Wilson, K. (1987). Preparation of genomic DNA from bacteria. In Current Protocols in Molecular Biology, pp. 2.4.1-2.4.5. Edited by F. M. 
Ausubel, R. Brent, R. E. Kingston, D. D. Moore, J. G. Seidman, J. A. Smith \& K. Struhl. New York: Green Publishing \& Wiley-Interscience.

Yamada, Y. \& Yukphan, P. (2008). Genera and species in acetic acid bacteria. Int J Food Microbiol 125, 15-24.

Yamada, Y., Katsura, K., Kawasaki, H., Widyastuti, Y., Saono, S., Seki, T., Uchimura, T. \& Komagata, K. (2000). Asaia bogorensis gen. nov., sp. nov., an unusual acetic acid bacterium in the $\alpha$ Proteobacteria. Int J Syst Evol Microbiol 50, 823-829.
Yukphan, P., Potacharoen, W., Tanasupawat, S., Tanticharoen, M. \& Yamada, Y. (2004). Asaia krungthepensis sp. nov., an acetic acid bacterium in the $\alpha$-Proteobacteria. Int J Syst Evol Microbiol 54, 313316.

Yukphan, P., Malimas, T., Potacharoen, W., Tanasupawat, S., Tanticharoen, M. \& Yamada, Y. (2005). Neoasaia chiangmaiensis gen. nov., sp. nov., a novel osmotolerant acetic acid bacterium in the $\alpha$-Proteobacteria. J Gen Appl Microbiol 51, 301-311. 